\title{
Impacto sonoro do aeroporto Santos Dumont/RJ: análise e medidas de controle
}

\author{
NETO, José R. de Lima \\ CARDOSO, Cláudio A. ${ }^{1}$ \\ ${ }^{1}$ Universidade Federal de São Carlos, São Carlos, Brasil. cardoso@df.ufscar.br
}

Resumo

A poluição sonora é parte cotidiana da vida nas grandes cidades. Dentre as fontes sonoras relevantes no contexto das cidades, tais como o ruído viário, uma que oferece desafios particulares é a relacionada ao sobrevoo de aeronaves, sejam aviões comerciais, jatos particulares ou helicópteros. Por se tratar de fontes intensas de ruído e das características das suas trajetórias (extensas e acima das habitações), tanto a avaliação do incômodo gerado, como eventuais medidas de mitigação são complexas e de difícil implementação.

Dessa forma, o desconforto acústico gerado nas comunidades próximas as rotas de pouso e decolagem de grandes aeroportos tornou-se alvo de grandes reclamações por parte dos moradores que tem seu conforto ameaçado, o que reforça a necessidade de enfrentar estes desafios e atacar este problema.

Assim, nesse trabalho, buscamos avaliar o impacto sonoro das aeronaves que possuem como destino ou são oriundas do aeroporto Santos Dumont/RJ (SBRJ), através de simulação computacional de ruído, em uma região próxima ao aeroporto com área de aproximadamente $39 \mathrm{~km}^{2}$. A partir da quantificação e determinação das áreas efetivamente afetadas pelo ruído aeronáutico, e da comparação dos valores obtidos com as normas da legislação brasileira, esse trabalho visa mapear possíveis regiões de conflito e fornecer informações que orientem possíveis medidas mitigadoras e de controle de ruído plausíveis para a realidade atual.

\begin{abstract}
Acoustic pollution is part of everyday life in big cities. Among the relevant sound sources in the context of cities, such as road noise, one that provides particular challenges is related to the overflight of aircraft, whether commercial airliners, private jets or helicopters. Since overflight noise is an intense noise source as well as the characteristics of their trajectories, both the evaluation of annoyance and possible mitigation measures are complex and difficult to implement. However, the generated acoustic discomfort in communities near the landing and takeoff routes to major airports became the target of major complaints from residents who have threatened their comfort, which reinforces the need to address these challenges and tackle this problem.

Thus, in this study we aim to assess the noise impact of aircraft that have come from as a destination or airport Santos Dumont / RJ through computer simulation of noise in a region close to the airport with an area of approximately $39 \mathrm{~km}$ 2. From the determination and quantification of the areas actually affected by aircraft noise, and comparing the values obtained with the standards of the Brazilian legislation, this paper aims to map out possible areas of conflict and provide information to guide possible mitigation and noise control measures.
\end{abstract}

Keywords: Acoustics, Noise Aircraft, Airports Impact Sound.

Palavras-Chave: Acústica, Ruído aeronáutico, Impacto Sonoro de Aeroportos. 


\section{Introdução}

Entender e controlar diferentes fontes de ruído no ambiente urbano é fundamental para garantirmos a saúde e qualidade de vida dos habitantes das grandes e médias cidades. Dentre as fontes sonoras relevantes nas grandes cidades, podemos citar o ruído gerado pelas construções, o ruído rodoviário e o ruído aeronáutico.

Em especial, o ruído aeronáutico tornou-se importante devido ao grande número de voos executados diariamente em cidades como São Paulo e Rio de Janeiro. As medidas do governo para reduzir os gargalos atuais de logística em um país continental como o Brasil, juntamente com a necessidade de preparar o país para sediar nos próximos anos a Copa do Mundo de Futebol (2014) e as Olímpiadas (2016), devem levar a uma significativa expansão dos aeroportos brasileiros e da demanda por voos nacionais e internacionais, o que acarreta em um número maior de aeronaves em operação em futuro próximo. Assim, o ruído aeronáutico, que já é crítico em algumas regiões, tende a piorar ainda mais nos próximos anos em diversas cidades brasileiras.

Um trabalho realizado no ano de 2012 por Nogueira e colaboradores (NOGUEIRA; SATTLER, 2012) expõe quão incômodo o ruído aeronáutico pode ser para uma comunidade. Este estudo mostra que $90 \%$ das pessoas, nas comunidades que ficam nas rotas de tráfego das aeronaves do Aeroporto Santos Dumont, percebem o ruído proveniente das aeronaves sempre ou frequentemente e que $94 \%$ classificam esse ruído como alto ou muito alto. Este resultado indica que o estudo de impacto sonoro é de extrema importância para garantir que as legislações vigentes sejam cumpridas e para projetar medidas de controle de ruído. O aeroporto Santos Dumont é o $6^{\circ}$ aeroporto mais movimentado do país em dois rankings: número de movimentos de passageiros e número de movimento de aeronaves (INFRAERO, 2012). Além disso, localiza-se em região central na cidade do Rio de Janeiro, próximo, portanto, de regiões densamente habitadas e de estruturas sensíveis a ruído, tais como hospitais e escolas. Estas características fazem do aeroporto Santos Dumont uma significativa fonte de ruído e incômodo para parte da população do Rio de Janeiro.

No presente trabalho, avaliamos o impacto sonoro do aeroporto Santos Dumont através de simulação computacional, realizada através do software CadnaA. Tal simulação terá como base o número médio de voos executados diariamente e as aeronaves que os executam, bem como a sua rota. Visando mensurar o impacto sonoro na comunidade, uma área de aproximadamente $39 \mathrm{~km}^{2}$ foi modelada com mais de 1043 obstáculos acústicos, além de topografia e diferentes áreas de absorção. A partir dos resultados obtidos, verificou-se a possível existência de conflitos com a legislação vigente e possíveis ações mitigadoras que poderiam ser adotadas para reduzir estes conflitos.

\section{Objetivo}

O objetivo deste artigo é quantificar e determinar o impacto sonoro nas áreas efetivamente afetadas pelo ruído aeronáutico proveniente das atividades de pouso e decolagem do aeroporto Santos Dumont/RJ, fazendo um comparativo com as normas brasileiras e posteriormente propondo medidas de controle.

\section{Método}

A metodologia utilizando nesse trabalho pode ser divida em basicamente três partes:

Simulação Computacional de ruído

Comparação dos níveis de ruído obtidos com a norma

Medidas de controle de ruído

\subsection{Simulação computacional de ruído}

No caso das simulações acústicas tem-se um grande desafio, pois quando se simula a propagação sonora em um ambiente externo temos muitas variáveis a ser consideradas para que o modelo computacional tenha um bom grau de acurácia. Como exemplo, podemos citar a dificuldade em inserir no modelo computacional de ruído todos os obstáculos geométricos que o som encontrará no seu caminho, além da topografia, número de reflexões, diferentes coeficientes de absorção do solo e condições meteorológicas.

Para a simulação computacional do aeroporto Santos Dumont e seu entorno, o software de modelagem acústica CadnaA v.4.2.140 foi utilizado. Trata-se de um software desenvolvido pela empresa alemã Datakustik $\mathrm{GmbH}$, que possui modelo de avaliação de impacto sonoro com base na norma ISO 9613-1 (1993): "Cálculo da absorção do som pela atmosfera" e ISO 9613-2 (1996): "Método de cálculo geral, para definição do modelo de propagação do ruído ao ar livre".

Nas simulações acústicas que envolvem aeroportos, os softwares de modelagem computacional são bastante úteis, visto que se torna praticamente inviável ter um mapa de ruído que demonstre toda a área atingida pelo ruído aeronáutico apenas com medições. O pacote complementar que permite 0 cálculo de impacto sonoro de rotas de aeronaves através do CadnaA é chamado de Option FLG - 
Aicraft Noise Calculation, que foi desenvolvido com base em procedimentos e leis internacionais. Os procedimento de cálculo utilizado pelo CadnaA-FLG, como por exemplo o ICAN/AzB 2008 (PROBST ; HUBER; VOGELSANG, 2009), foram aprovados pela German Federal Environment Agency (UBA) e testes de casos, além de terem sido feitos com base nas ISO 9613-1 (1993) e ISO 9613-2 (1996). Os parâmetros disponíveis para configurar os cálculos utilizados pela CadnaA-FLG dependem do procedimento selecionado. No caso de um procedimento que tem diretrizes específicas de cálculos, como o ICAN (Instruction for the Calculation of the Aircraft Noise and for noise mapping around airports), os parâmetros de cálculo já se encontram adequados ao procedimento, quando o mesmo é selecionado. A ICAN conta uma base de mais de 41 grupos de aeronaves e em cada um desses grupos existe duas classes para diferenciar o ruído emitido no pouso e decolagem. Em cada uma dessas classes, a emissão sonora é definida como uma pressão sonora a uma determinada distância e três coeficientes para caracterizar a diretividade. O perfil vertical das rotas de voo é definido em alguns pontos específicos e os demais são interpolados linearmente, sendo que todas essas alturas são definidas relativamente ao terreno digital construído e, para cada um desses segmentos, a velocidade da aeronave e um nível de correção são redefinidos.

A construção do modelo computacional do aeroporto Santos Dumont e seu entorno foi realizada a partir de uma imagem georeferrenciada obtida através do software Google Earth que foi posteriormente importada para o software de modelagem acústica CadnaA v.4.2.140. A imagem importada para o software possuía as marcações que dividiam todos os bairros da cidade do Rio de Janeiro e seu tamanho foi previamente escolhido tendo como base a área que se queria modelar, que nesse caso se concentrava nos bairros Botafogo, Flamengo, Laranjeiras, Santa Tereza e Urca, visto as reclamações previamente conhecidas pelos autores do trabalho (NOGUEIRA; MANSUR; SATTLER, 2012).

Após a importação da imagem inicial, começou-se o modelamento geométrico, que consistiu basicamente em modelar computacionalmente todos os obstáculos acústicos existentes na imagem. Foram então modelados computacionalmente mais de 1043 obstáculos seguindo o georreferenciamento da imagem para colocar os obstáculos no devido lugar. Utilizou-se de um marcador para identificar cada um dos obstáculos modelados para uma posterior análise por bairros, além de configurar alturas diferentes para determinadas regiões. De acordo com o observado pelo Google Earth, as edificações centrais possuem alturas maiores do que as edificações das regiões mais afastadas e, através dessa observação realizada por bairros, configuraram-se diferentes alturas para os obstáculos geométricos. A imagem foi também utilizada para definir zonas de diferentes absorções acústicas como, por exemplo, o mar às margens dos bairros do Centro, Glória, Flamengo, Botafogo e Urca e a mata próxima aos bairros Cosme Velho e Humaitá.

Através do software Global Mapper obteve-se a topografia local por meio de curvas de níveis que foram importadas para o software de modelagem acústica. A combinação de todos estes elementos originou a modelagem da região de interesse para a simulação, como pode ser observado na Figura 1.

As pistas do aeroporto foram configuradas pelo modo FLG Aircraft Noise Calculation no software de modelagem acústica com as medidas técnicas levantadas. O próximo passo foi determinar a rota a ser seguida pelas aeronaves. Esse levantamento foi realizado através de uma consulta na internet (AIS, 2012) das cartas visuais de aproximação das aeronaves. Muito embora haja algumas pequenas variações nas rotas aéreas seguidas pelas aeronaves, podemos classificá-las basicamente em dois grupos, de acordo com a direção vento (fator extremamente importante tanto para pouso quanto para decolagem).

Os pousos ou decolagem sempre ocorrem em sentido contrário ao vento, para evitar que alguma rajada de vento na parte traseira da aeronave a desestabilize. Dessa forma, existem duas rotas básicas para pouso e duas rotas básicas para decolagem, ou seja, todas as aeronaves serão alocadas nessas 4 rotas oficiais

Figura 1: Visualização do modelo computacional em 3D, detalhe para o aeroporto no canto esquerdo da figura.

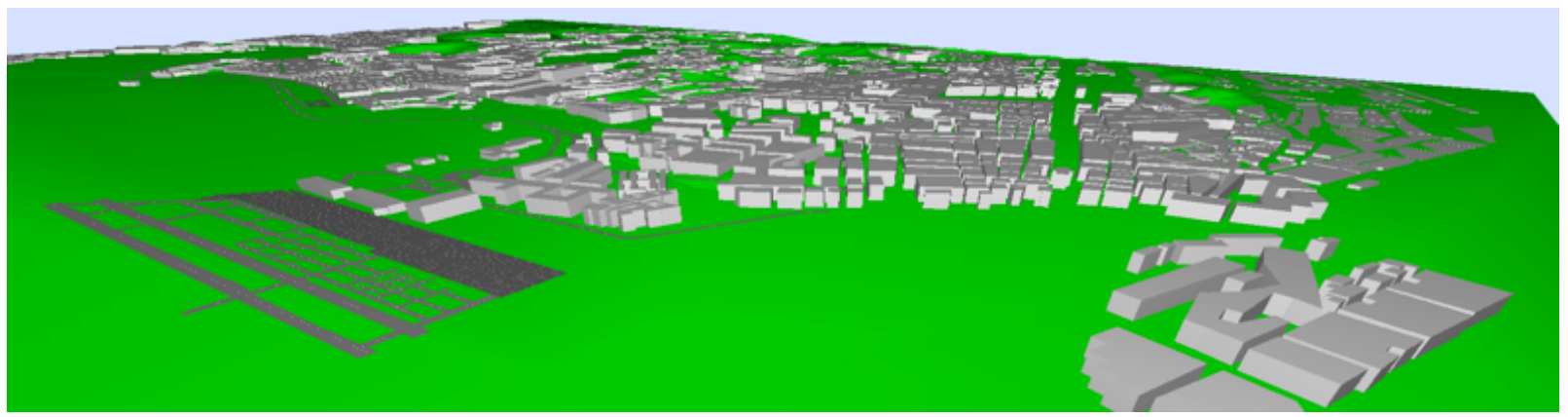

Fonte: Oliveira (2006) 
(AIS, 2012) nesse modelo computacional. Logicamente existem variações tanto para pouso quanto para decolagem, porém as mesmas não serão consideradas nessa simulação. No caso do sentido do vento estar no sentido de norte para sul o pouso e a decolagem ocorrerão no sentido de sul para norte. As rotas que demonstram tais operações são exibidas na Figura 2, sendo que a rota em vermelho é a representação do pouso $(\mathrm{P} 1)$ e a rota em azul representa a decolagem (D1). Já para o caso do sentido do vento estar no sentido de sul para norte o pouso e a decolagem ocorrerão no sentido de norte para sul. As rotas que demonstram tais operações são exibidas na figura abaixo, sendo que a rota em vermelho é a representação do pouso (P2) e a rota em azul representa a decolagem (D2).

Com a rota que as aeronaves irão seguir inseridas no modelo computacional, passa-se então a analisar as aeronaves que pousam e decolam no aeroporto Santos Dumont, pois dependendo do tamanho, peso e motor das aeronaves elas devem ser classificadas em grupos diferentes de aeronaves de acordo com os grupos definidos pelo FLG Aircraft Noise Calculation no software de simulação acústica.

Através de um estudo feito pela Fundação COPPETEC (2009), foi possível obter os dados de todas as aeronaves que pousam e decolam no aeroporto Santos Dumont com a média de número de voos por dia, como apresentado na Tabela 1.
Para inserção de tais aeronaves no modelo computacional, busca-se semelhanças entre as mesmas e a descrição do grupo de aeronaves apresentados no modo FLG Aircraft Noise. O grupo de aeronaves leva em consideração parâmetros como, por exemplo, se a aeronave possui turbina ou hélice, peso da aeronave, massa de decolagem, extensão e mais alguns outros parâmetros.

Os números de pousos e decolagens por período e por grupo de aeronaves foram calculados tendo como base a Tabela 1, juntamente com os dados oficiais da Infraero fornecidos em seu anuário (INFRAERO, 2012). Estimou-se qual a participação percentual de cada aeronave e dessa forma, com o número de voos e decolagem (proporção de um para um), pôde-se obter quantos voos e decolagem eram executados por ano por cada aeronave. Através do horário de funcionamento do aeroporto fez-se então uma estimativa de quantos voos eram executados por cada aeronave em cada período do dia. A Tabela 2 sintetiza os grupos em que as aeronaves foram classificadas e seus respectivos números de pouso e decolagem por período.

Muito embora o modo FLG estipule alturas de acordo com o comprimento das rotas, levando em consideração a velocidade e a capacidade de aceleração das mesmas, prefere-se para algumas rotas inserir o perfil de descida das aeronaves através das cartas de aproximação por instrumentos (IAC), tendo dessa forma uma situação mais próxima do real (AIS, 2012). A Figura 3 ilustra um dos perfis de descida utilizados.

Figura 2: Rotas de pouso e decolagem consideradas na simulação.

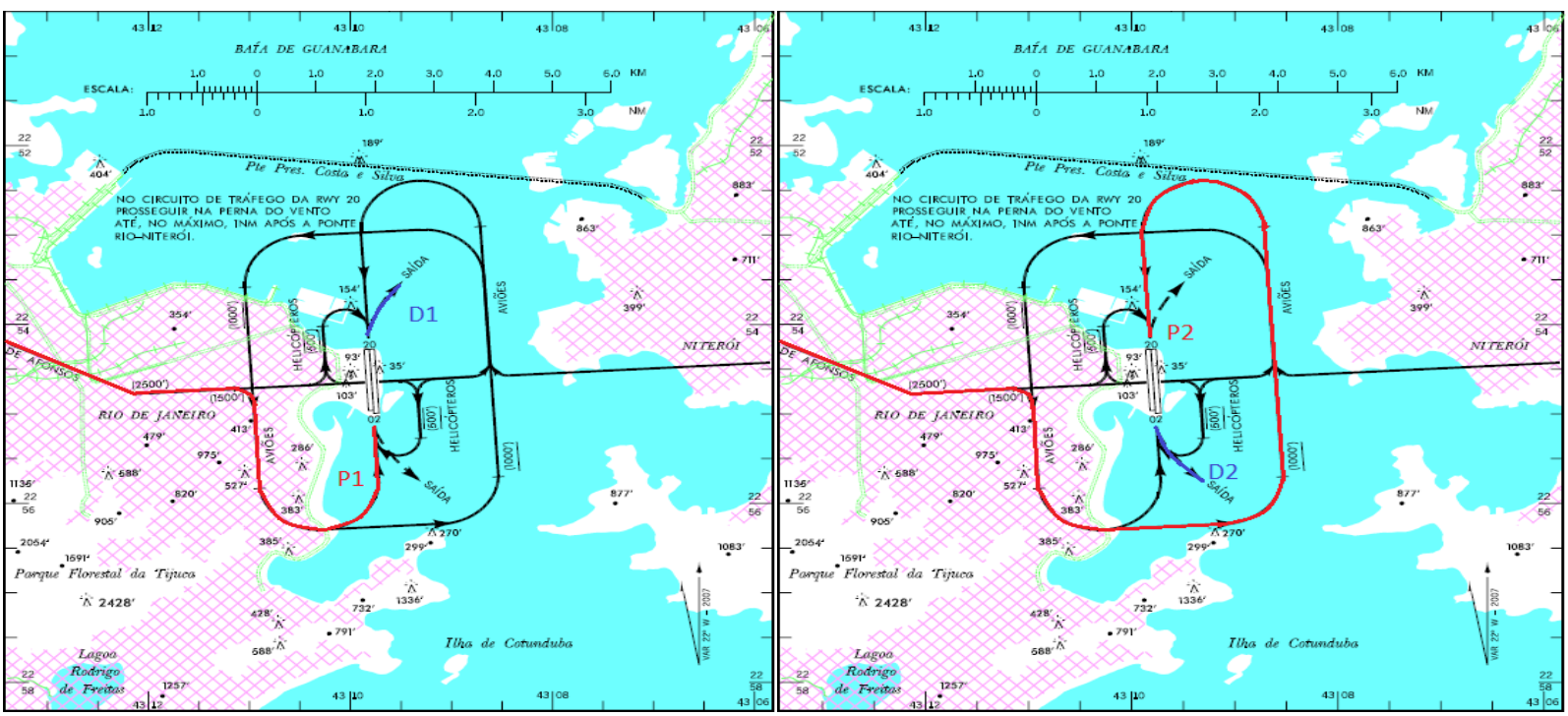

Tabela 1: Média de número de voos por dia (Fundação COPPETEC, 2009).

\begin{tabular}{|c|c|c|c|c|c|c|c|c|c|}
\hline Aeronaves & 737300 & 737700 & 737800 & A319 & ATR42 & EMB120 & EMB190 & F10065 & GASEPEV \\
\hline $\begin{array}{c}\mathrm{N}^{0} \text { de voos média } \\
\text { por dia }\end{array}$ & 8,452 & 25,032 & 5,903 & 31,323 & 3,387 & 2,774 & 5,839 & 8,032 & 7,258 \\
\hline
\end{tabular}


computacional, realizou-se asimulação computacional do impacto sonoro, considerando todas as rotas divididas nos períodos diurno e noturno. O período noturno teve seu modelo computacional posteriormente calibrado.

\subsection{Comparação dos níveis de ruído obti- dos com a norma}

Uma vez completa a simulação e tendo o mapa sonoro da região sob estudo, realizou-se uma avaliação do impacto sonoro do aeroporto frente aos níveis critério definidos pela normativa NBR 10151 (2000). Para tanto, obtivemos um mapa de inconformidade ao subtrairmos os níveis critério para cada utilização particular do espaço urbano do mapa sonoro obtido pela simulação. Tal processo foi repetido para os períodos diurno e noturno. Posteriormente, se verificou se havia, nas regiões de inconformidade, edificações cujo uso correspondesse ao nível critério utilizado (escolas, hospitais, moradias, zonas mistas, etc) e que assim estivessem expostas a um ruído excessivo frente o previsto em norma.

\subsection{Medidas de controle de ruído}

Finalmente, uma vez constatada uma inconformidade com a normativa NBR 10151 (2000), apresentamos como possível medida mitigadora para reduzir o problema do ruído excessivo devido ao tráfego aéreo do aeroporto Santos Dumont a utilização de uma rota alternativa para pousos e decolagens que evite 0 sobrevoo da cidade.

\section{Análise e discussão dos resultados}

A seguir serão apresentados os resultados obtidos nesta pesquisa. As simulações apresentadas foram obtidas utilizando a metodologia descrita na seção anterior e apresenta o nível sonoro equivalente para o período em consideração.

\subsection{Mapas de ruído}

As simulações do impacto sonoro dos pousos e decolagens de aeronaves no aeroporto Santos Dumont estão apresentadas na Figura 4, para os períodos diurno e noturno. Juntamente com o mapa de ruído são apresentadas também as rotas de pouso e decolagem utilizadas na simulação.

Pode-se perceber na cartografia acústica apresentada a forte influência acústica que as rotas possuem, visto que as curvas de ruído acompanham de forma clara as rotas das aeronaves. É notório também que as curvas de maior pressão sonora encontram-se no interior do aeroporto, como esperado, e que o interior da cidade é atingido por regiões maiores que $50 \mathrm{~dB}(\mathrm{~A})$ devido às rotas de pousos, o que faz de tais rotas de pouso objeto de estudo para medidas mitigadoras. $\mathrm{O}$ mapa de ruído noturno (22:00 - 07:00) foi calculado tendo como base todas as decolagens e pousos que acontecem nas duas horas de operação do aeroporto no período noturno, o que faz com que os níveis encontrados em tal período sejam bem menores do que os encontrados no período diurno. Esta redução pode ser vista como uma subavaliação do ruído

Tabela 2: Número de aeronaves por pouso e decolagens em períodos.

\begin{tabular}{|c|c|c|c|c|c|c|c|c|c|}
\hline \multirow{2}{*}{ Aeronaves } & \multicolumn{3}{|c|}{ S 1.2} & S 5.2 & P 2.1 & \multicolumn{3}{c|}{ P 1.4 } & S 5.1 \\
\cline { 2 - 10 } & GASEPEV & 737300 & 737700 & 737800 & A319 & ATR42 & EMB120 & EMB190 & F10065 \\
\hline Porcentagem & $7,41 \%$ & $8,62 \%$ & $25,54 \%$ & $6,02 \%$ & $31,96 \%$ & $3,46 \%$ & $2,83 \%$ & $5,96 \%$ & $8,20 \%$ \\
\hline $\mathbf{N}^{\mathbf{0}}$ de pouso e decolagem ao ano & 4800 & 5590 & 16555 & 3904 & 20716 & 2240 & 1835 & 3862 & 5312 \\
\hline $\mathbf{N}^{\mathbf{0}}$ de pouso ao ano - Diurno & \multicolumn{3}{|c|}{28583} & 19194 & 2076 & 5278 & 4922 \\
\hline $\mathbf{N}^{\mathbf{0}}$ de pouso ao ano - Noturno & \multicolumn{3}{|c|}{2266} & 1522 & 165 & 418 & 390 \\
\hline $\mathbf{N}^{\mathbf{0}}$ de decolagem ao ano - Diurno & \multicolumn{3}{|c|}{28272} & 18985 & 2053 & 5220 & 4868 \\
\hline $\mathbf{N}^{\mathbf{0}}$ de decolagem ao ano - Noturno & \multicolumn{3}{|c|}{1731} & 187 & 476 & 444 \\
\hline
\end{tabular}

Figura 3: Perfil de descida para a rota de pouso P1 (AIS, 2012).

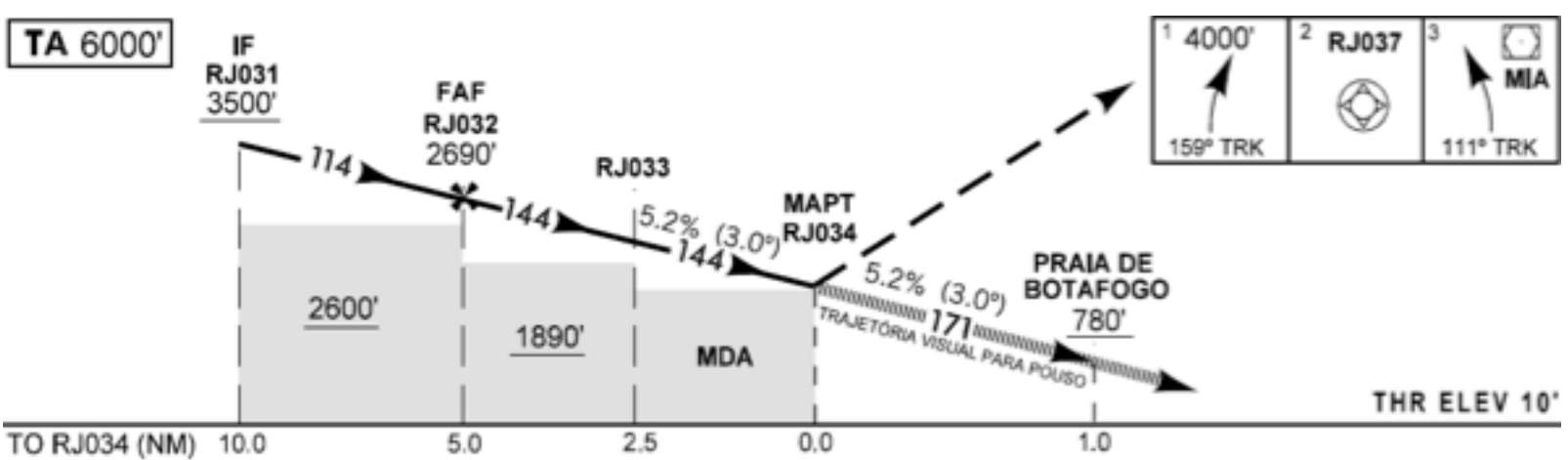


Figura 4: Mapa de ruído devido ao ruído aeronáutico do SBRJ durante o período diurno e noturno.

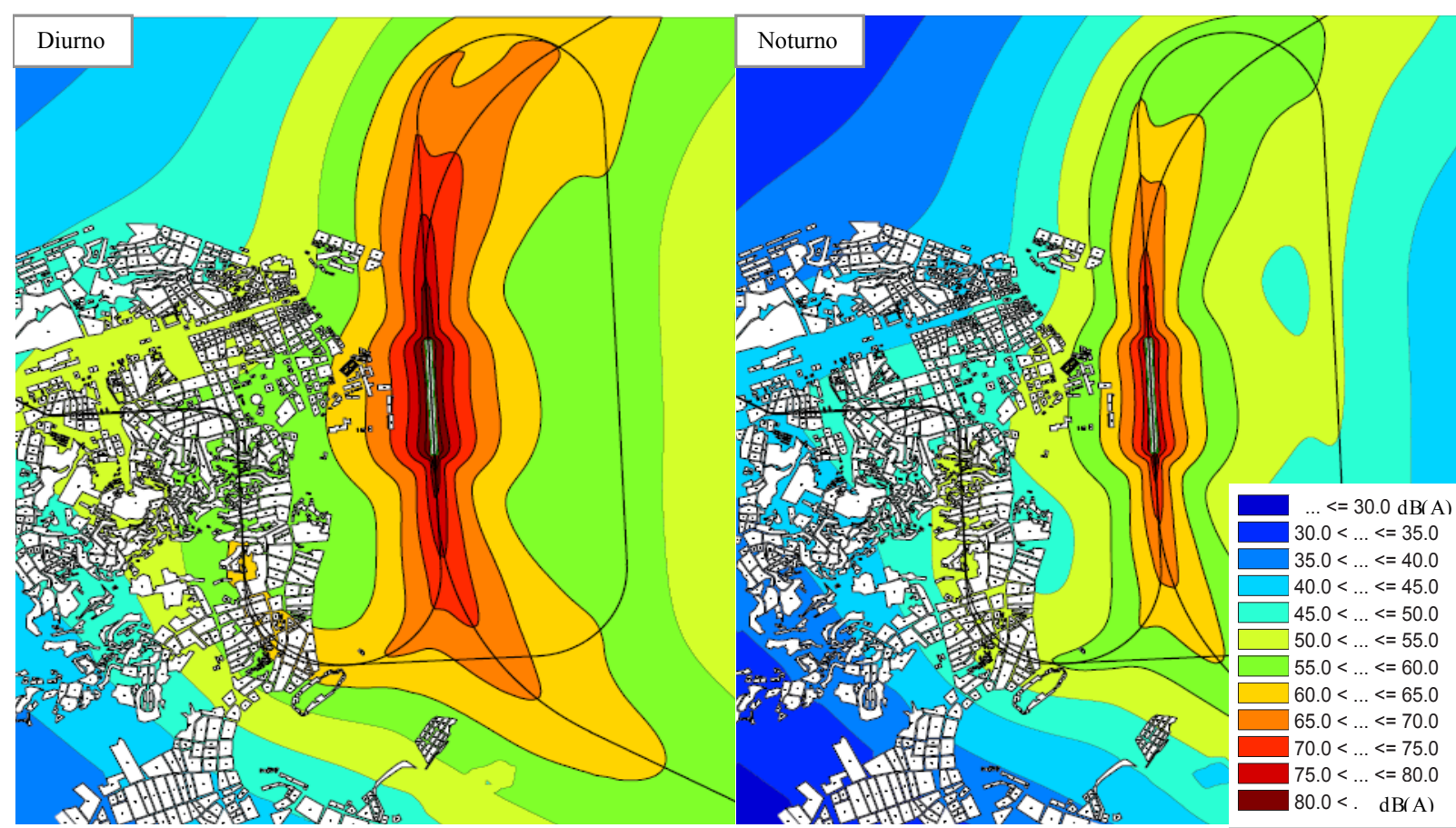

noturno, já que o incômodo gerado pelos pousos e decolagens nas duas horas de operação do aeroporto no período noturno deve ser significativo, ainda que o nível global para todo o período seja menor que o observado no período diurno. Assim, pode-se questionar se medidas globais são efetivamente boas formas de avaliação do incômodo causado, ou se a análise deveria levar em consideração intervalos de tempo menores para as simulações. Por outro lado, avaliações feitas apenas considerando os momentos de pico certamente levaria a uma significativa sobreavaliação dos níveis sonoros. Assim, uma discussão mais aprofundada da adequação da aplicação direta da norma na avaliação do nível sonoro, ou sobre um procedimento mais apropriado para se obter resultados que reflitam o incômodo causado na população de uma forma mais acurada, é necessária e deverá ser implementada em um trabalho futuro.

\subsection{Comparação dos níveis de ruído obti- dos com a norma}

A normativa NBR 10151 (2000) estabelece níveis de critério de avaliação para o período diurno (07:00 22:00) e noturno (22:00 - 07:00). Para ilustrar o procedimento adotado, apresentaremos neste artigo apenas os resultados obtidos quando o critério a ser avaliado será o critério para "Área estritamente residencial urbana ou de hospitais ou de escola".

Partindo do resultado apresentado na Figura 4, que apresenta o mapa de ruído que dá o impacto total das rotas para o período diurno e noturno, subtraímos os níveis de critérios estabelecidos pela NBR 10151 (2000) para cada período correspondente, a saber, 50 $\mathrm{dB}(\mathrm{A})$ para o período diurno e $45 \mathrm{~dB}(\mathrm{~A})$ para o período noturno. Dessa forma, as regiões que apresentam ruído acima do estabelecido pela NBR 10151 (2000) para esse critério são as regiões coloridas, as regiões em branco são as que se encontram abaixo do permitido.

Podemos observar que há um significativo excesso de ruído em grande parte da região analisada, tanto no período diurno, quanto noturno. Pode-se observar que as regiões de inconformidade seguem proximamente a rota de pouso que sobrevoa a cidade. Entretanto, é importante notar que o nível critério adotado é o mais restritivo, de tal forma que era esperável que a inconformidade obtida fosse elevada.

A próxima etapa então é a verificação se de fato existem edificações de tal classificação na área acima do critério estabelecido. Através do Google Earth, constata-se a existência de escolas e hospitais nas regiões coloridas. São encontrados pelo menos cinco hospitais e três instituições estudantis nas áreas coloridas, como apresentado na Figura 6. Nota-se que a Casa de Saúde São Sebastião encontra-se em região de 9 a $12 \mathrm{~dB}(\mathrm{~A})$ de inconformidade com a NBR 10151 (2000) para o período diurno. De acordo com a figura apresentada, pode-se avaliar que muitos hospitais e escolas recebem ruído que estão acima do permitido pela norma devido ao ruído aeronáutico, exigindo assim medidas mitigadoras. Diante do que foi apresentado, pode-se notar que as rotas de pouso que passam pelo interior da cidade fazem com que os níveis de critérios mais restritivos sejam ultrapassados, dessa forma tais rotas devem ser estudadas afim de uma melhora acústica no interior da cidade.

Do mesmo modo realizado para este critério, analisouse todos os outros critério da NBR 10151 (2000) aplicáveis e pode-se perceber que alguns critérios 
Figura 5: Região de inconformidade com a NBR 10151 (2000) para o critério "Área predominantemente residencial urbana ou de hospitais ou de escolas".

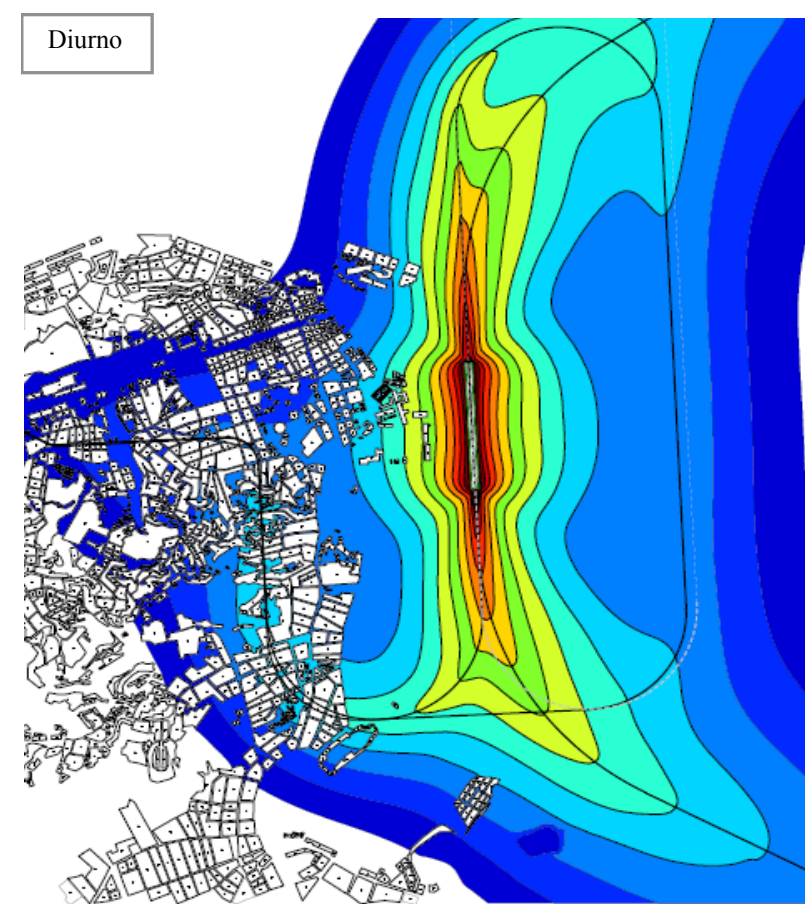

são ultrapassados em grandes áreas devido a essas rotas, enquanto para outros critérios encontra-se pequenas áreas de inconformidade, ou até mesmo estando em conformidade em toda a área estudada. A Tabela 3 sintetiza a análise comparativa com a NBR 10151 (2000).

É válido ressaltar que a abordagem aqui adotada mostra as regiões que estariam em conformidade ou inconformidade com os níveis de critério da NBR 10151(2000), supondo que todo o interior da cidade fosse classificado de uma mesma forma, para depois disso procurar edifícios que de fato sejam característicos de tal critério na região acima do permitido. Essa estratégia foi adotada devido à dimensão da simulação computacional (aproximadamente $39 \mathrm{~km}^{2}$ ), pois é muito mais eficaz definir as regiões que se encontram acima de determinado critério e depois rastrear evidências que comprovem que uma determinada área de fato é coerente com tal classificação.

Todas as considerações feitas aqui levam em conta um dia de operação do aeroporto Santos Dumont distribuído de forma proporcional entre os períodos diurno e noturno, lembrando que medidas pontuais de curta duração podem possuir valor global ponderado em A bastante diferente dos obtidos por simulação computacional, pois dessa forma o incômodo gerado pelo pico de ruído das aeronaves durante suas passagens não são diluídos durante o período de tempo da medida onde não há passagens.

\subsection{Medidas de controle de ruído}

Diante do que foi apresentado vemos que as reclamações com respeito ao aeroporto Santos Dumont possuem

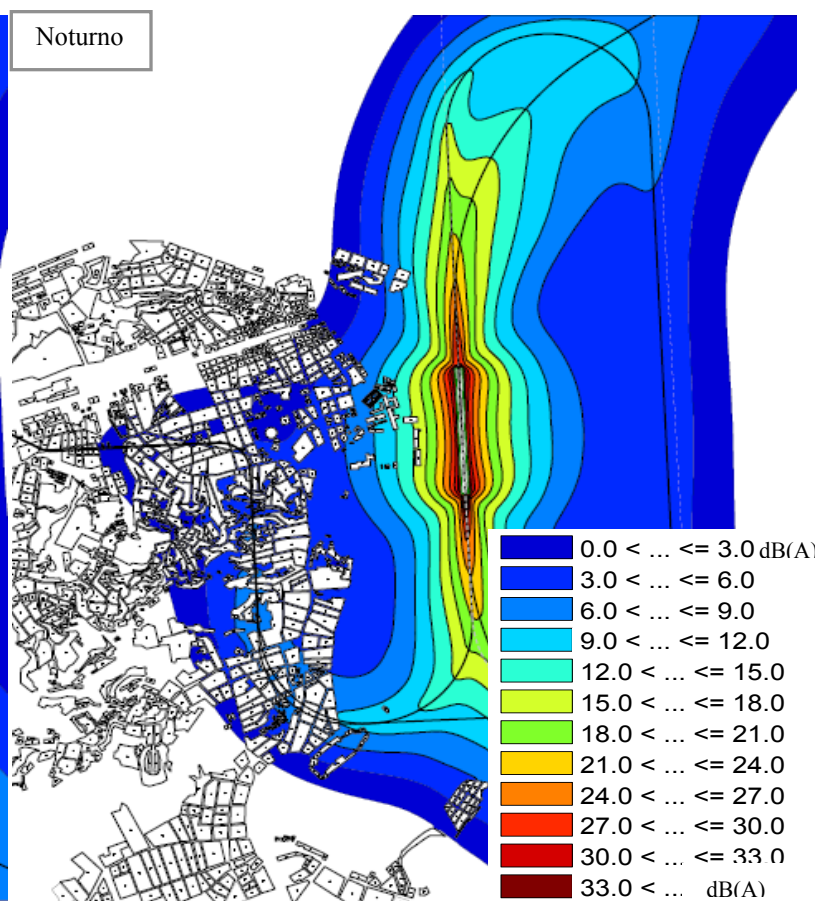

fundamento e que, de acordo com as análises feitas pela NBR 10151 (2000), existem regiões de inconformidades devido ao aeroporto. No intuito de propor medidas de controle de ruído para garantir o conforto acústico da população nas rotas do aeroporto, algumas medidas de controle foram pesquisadas e analisadas.

O controle do ruído pode operar na fonte geradora do ruído, no caminho de propagação do mesmo, ou junto ao receptor. Como o receptor no caso seriam todas as edificações em toda esta região da cidade, não é razoável propor soluções que passem por melhorar o isolamento acústico de todas estas edificações, ainda que tal solução possa ser adotada em casos pontuais específicos. Da mesma forma, a redução do ruído na fonte passa pelo projeto e construção de aeronaves mais silenciosas, o que certamente está além do escopo deste trabalho. Focaremos, assim, na discussão de como reduzir o impacto sonoro alterando - caminho de propagação do som, através de alterações na rota das aeronaves.

\subsubsection{Alterações no Caminho de Propagação}

O caminho percorrido pelo ruído até as comunidades está intimamente ligado com a fonte sonora, as aeronaves. Dessa forma, quando se fala em medidas mitigadoras de ruído para o caminho, está se falando diretamente sobre o caminho que a fonte sonora realiza.

De acordo com a simulação computacional realizada nesse trabalho, vemos que as rotas que possuem grande influência sobre o interior da cidade são as rotas de pouso, visto que as rotas de decolagem oficiais não passam pelo interior da mesma. Dessa forma, uma das medidas de controle com respeito ao caminho do ruído será a modificação das rotas de pousos. 
Figura 6: Presença de hospitais e escolas na região acima de $50 \mathrm{~dB}(\mathrm{~A})$.

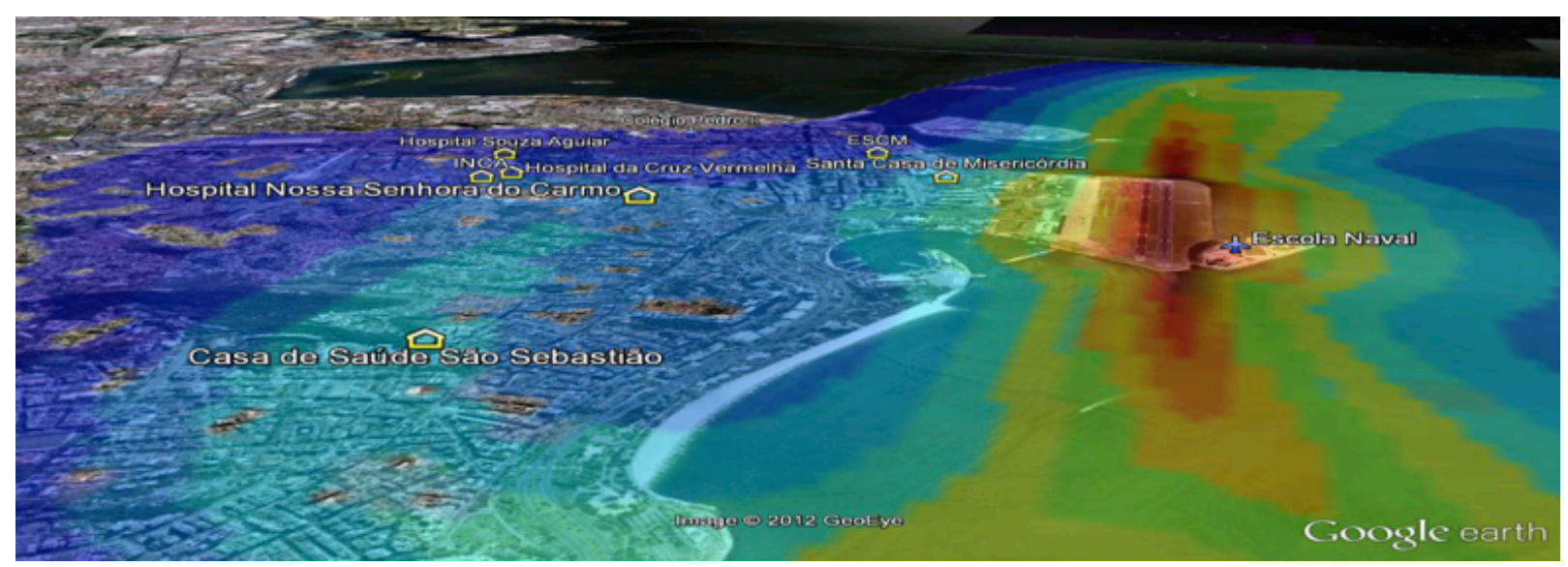

Tabela 3: Status das áreas no interior da cidade

\begin{tabular}{|c|l|c|}
\hline Critério & \multicolumn{1}{|c|}{ Tipos de área } & Status nas áreas no interior da cidade \\
\hline 2 & Área estritamente residencial urbana ou de hospitais ou de escolas & Grande região de Inconformidade \\
\hline 3 & Área mista, predominantemente residencial & Média região de Inconformidade \\
\hline 4 & Área mista, com vocação comercial e administrativa & Pequena região de Inconformidade \\
\hline 5 & Área mista, com vocação recreacional & Conformidade \\
\hline 6 & Área predominantemente industrial & Conformidade \\
\hline
\end{tabular}

Obviamente que a mudança de uma rota aeronáutica não é tão simples de ser realizada, visto que existem muitos fatores a serem considerados. Entretanto, pensando na questão do ruído, uma mudança das rotas de pouso traria sim grandes ganhos a comunidade que estão em suas rotas. Realizou-se uma simulação computacional com duas rotas de pouso, para ambas as direções do vento, e tais rotas não passam pelo interior da cidade com altura suficiente para gerar ruído perceptível. De fato, ao adotar uma rota que se aproxime do aeroporto pelo mar pode-se manter a fonte sonora muito mais afastada das regiões habitadas, e assim ter um nível sonoro da cidade bastante inferior do que é observado para rotas que sobrevoam a cidade.

A partir dessa simulação computacional com novas rotas retirou-se a simulação feita anteriormente com as rotas de pousos, obtendo assim um mapa que exemplifica em quantos $\mathrm{dB}(\mathrm{A})$ as novas rotas melhoram o ruído no interior da cidade. Esse mapa de ganho já sintetiza o período diurno e noturno através da métrica DNL (Day Night Level). A métrica DNL é comumente utilizada entre comparações acústicas de aeroportos, e é capaz de sintetizar as informações de ruído contidas nos mapas de ruído de um período diurno e noturno em um único mapa, através da soma ponderada (penalidade de $10 \mathrm{~dB}(\mathrm{~A})$ para o período noturno) dos valores globais de cada período, através da seguinte equação:

$D N L=10 \log _{10}\left\{\frac{1}{24}\left[\sum_{1}^{15} 10^{\frac{L A e q D}{10}}+\sum_{1}^{9} 10^{\frac{L A e q N+10}{10}}\right]\right\}$
Onde:

LAeqD é o nível equivalente global ponderado em $A$ para o período diurno $[\mathrm{dB}(\mathrm{A})]$;

LAeqD é o nível equivalente global ponderado em $A$ para o período noturno $[\mathrm{dB}(\mathrm{A})]$.

De acordo com o mapa de ganho vemos que existe uma melhora por todo o interior simulado da cidade de pelo menos $6 \mathrm{~dB}(\mathrm{~A})$ chegando em grandes regiões de $21 \mathrm{~dB}(\mathrm{~A})$. Pode-se notar também que houve uma pequena região que atingiu melhoras de $27 \mathrm{~dB}(\mathrm{~A})$ que corresponde ao máximo de ganho que a mudança de rotas pode ter como resultado de acordo com a simulação. Dessa forma, pode-se concluir que a mudança das rotas constitui uma medida de controle bastante importante e efetiva, visto que a simples mudança do caminho das aeronaves provoca uma diminuição bastante significativa do nível sonoro no interior da cidade.

Ainda pensando em medidas mitigadoras para 0 caminho do ruído produzido pelas aeronaves, foi divulgado recentemente uma nova tecnologia/modo de pouso que tem como princípio a descida contínua, constante e com menos utilização do motor na descida das aeronaves para o pouso (AGENCIA BRASIL, 2011)

Essa tecnologia já está sendo utilizada desde o dia 5 de Maio de 2012 e está fundamentada no conceito RNP AR - Desempenho de Navegação Requerida com Autorização Requerida - em que a aeronave se utiliza da 
orientação de satélites para realizar a sua aproximação. O Boeing 737-800, que se encontra no grupo de aeronaves mais ruidosas, já está utilizando a tecnologia (DECEA, 2012). É válido lembrar que, para utilizar tal tecnologia, as aeronaves devem estar equipadas adequadamente e cumprir uma série de requisitos. Dessa forma, o processo para que todas as aeronaves contenham tal tecnologia deve se estender durante algum tempo. Atualmente existem basicamente 4 grupos de aeronaves, as não certificadas (NC) que foram fabricadas nas décadas de 50 e 60 equipadas com motores de $1^{\text {a }}$ geração e que são extremamente ruidosas, as aeronaves de segunda geração de motores que foram fabricadas nas décadas de 70 e 80 e que são menos ruidosas que as NCs, as aeronaves de $3^{a}$ geração de motores que foram fabricadas a partir da década 90 que já são mais modernas e são consideradas pouco ruidosas e pelas aeronaves equipadas com os motores de última geração e que são atualmente as menos ruidosas (ROCHA; SLAMA, 2008). Dessa forma o uso de aeronaves com motores de uso de última geração também traz significativo ganho em termos de poluição sonora.

\section{Conclusões}

A partir do trabalho de simulação computacional realizado, podem-se definir curvas de ruído geradas pela operação do aeroporto Santos Dumont ${ }^{1}$ quantificando dessa forma o impacto sonoro do aeroporto sobre a área simulada. Geraram-se curvas de pressão sonora equivalente ponderadas em A para os períodos diurnos e noturno além de curvas de ruído seguindo a métrica DNL, e a partir dessas curvas pode-se comparar o impacto sonoro do aeroporto com as normas e legislações vigentes.

Para NBR 10151 (2000) foram encontradas inconformidades, em especial para a área de hospitais e escolas. No sentindo de trazer ideias de medidas mitigadoras de ruído, foi proposto nesse trabalho alteração na rotas de pouso que sobrevoam a cidade. Realizou-se então uma simulação computacional com rotas que não passariam pelo interior da cidade em altura suficiente para gerar ruído perceptível e tendo como preferência a chegada pelo mar. Nessas rotas simuladas houve melhoras no interior simulado da cidade de até $27 \mathrm{~dB}(\mathrm{~A})$.

Por fim a última melhoria do ruído proposta age diretamente sobre a fonte, elucidando os procedimentos mais modernos e ressaltando que o uso de aeronaves equipadas com motores de última geração pode contribuir para uma melhora acústica.

E, por fim, é válido ressaltar que a simulação computacional realizada nesse trabalho não é de fato uma reprodução idêntica do aeroporto, pois foram

Comumente denominado SBRJ feitas uma série de considerações no decorrer do trabalho as quais geram uma incerteza. Ainda assim, pode-se observar que o nível de ruído gerado pelo sobrevoo de aeronaves é bastante significativo, especialmente se considerarmos que esta não é a única fonte sonora a que os moradores da região sob estudo estão submetidos. De fato, se considerarmos as contribuições devido ao trânsito viário, dentre outras, certamente regiões em que o nível sonoro do tráfego aéreo está dentro apenas do aceitável passarão a apresentar inconformidades.

\section{Referências bibliográficas}

ABNT - ASSOCIAÇÃO BRASILEIRA DE NORMAS TÉCNICAS. NBR 10151: Acústica - Avaliação do ruído em áreas habitadas, visando o conforto da comunidade - Procedimento. Rio de Janeiro, 2000.

AGENCIA BRASIL. Controle Aéreo vai usar tecnologia de última geração para reduzir barulho no Santos Dumont. Disponível em: \ttp://agenciabrasil.ebc.com.br/noticia/2011-10-06/ controle-aereo-vai-usar-tecnologia-de-ultima-geracao-para-reduzirbarulho-no-santos-dumont . Acesso em: 5 jan. 2013.

AIS - SERVIÇO DE INFORMAÇÃO AERONÁUTICA. Carta de aproximação visual localidade SBRJ tipo VAC. Disponível em: <http://www.aisweb.aer.mil. br/?i=cartas>. Acesso em: 25 nov. 2012.

Figura 7: Mapa de ganho relativo a troca das rotas de pouso em curvas DNL.

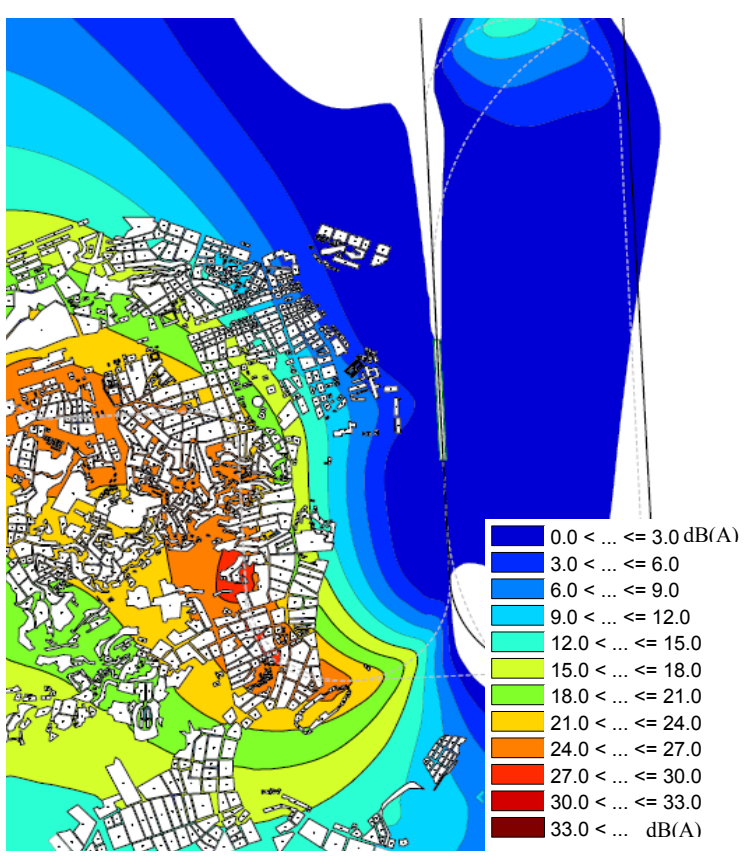

DECEA - DEPARTAMENTO DE CONTROLE DO ESPAÇO AÉREO. Menos ruído e mais capacidade: DECEA inaugura novos procedimentos de aproximação. Disponível em: <http://www.decea.gov.br/2012/05/07/menos-ruido-e-maiscapacidade-decea-inaugura-novos-procedimentos-de- 
aproximacao/>. Acesso em 5 jan. 2013.

FUNDAÇÃO COPPETEC - Fundação Coordenação de Projetos, Pesquisas e Estudos Tecnológicos. Campanha de monitoramento do aeroporto Santos Dumont. Rio de Janeiro, anexo 6, Dez. 2009.

ISO - INTERNATIONAL ORGANIZATION FOR STANDARDIZATION. ISO 9613-1: Attenuation of sound during propagation - Part 1: Calculation of the absorption of sound by the atmosphere. 1993a.

ISO 9613-2: Acoustics - Attenuation of sound during propagation-Part 2: General method of calculation. 1996b.

INFRAERO - Empresa Brasileira de Infraestrutura Aeroportuária. Anuário Estatístico Operacional 2011. Disponível em: 〈http:/www.infraero.gov.br/images/stories/ Estatistica/anuario/anuario_2011_2.pdf >. Acesso em: 20 out. 2012.

NOGUEIRA, R. DE C. C.; MANSUR, W. J.; SATTLER, M. A. Community Response to Noise and Environmental Noise Impact Assessment According Noise Pollution Legislations on Neighborhoods of Santos Dumont Airport in Rio de Janeiro, Brazil. Inter noise. New York, USA, ago 2012. Disponível em: <http://www.internoise2012. com/s. Acesso em: 11 nov. 2012.

PROBST W.; HUBER B.; VOGELSANG B. ICAN Instruction For The Calculation Of Air-Craft Noise And For Noise Mapping Around Airports. ICSV16, Kraków, Poland, 5-9 July 2009. Disponível em: <http//www. datakustik.com/fileadmin/user_upload/PDF/Papers/Paper_ CalculationAircraftNoise_Probst_ICSV16.pdl\$. Acessoem:22out.2012

ROCHA, R. DE B., SLAMA, J. G. Adequação Do Zoneamento Urbano Ao Zoneamento Sonoro Dos Aeroportos. Sitraer 7 629-640 - Tr. 512, Rio de Janeiro, nov. 2008. 